\title{
Configurações
}

Revista de sociologia

$9 \mid 2012$

Trabalho e género: vidas precárias, percursos e acção colectiva

\section{Contextos, discursos e percursos na delinquência juvenil feminina}

Contexts, discourses and pathways in female juvenile delinquency

Contextes, discours et parcours de la délinquance juvénile féminine

\section{Vera Duarte}

\section{OpenEdition \\ Journals}

\section{Edição electrónica}

URL: http://journals.openedition.org/configuracoes/1148

DOI: 10.4000/configuracoes. 1148

ISSN: 2182-7419

\section{Editora}

Centro de Investigação em Ciências Sociais

\section{Edição impressa}

Data de publição: 30 Junho 2012

Paginação: 121-133

ISSN: 1646-5075

\section{Refêrencia eletrónica}

Vera Duarte, "Contextos, discursos e percursos na delinquência juvenil feminina », Configurações [Online], 9 | 2012, posto online no dia 27 novembro 2013, consultado o 01 maio 2019. URL : http:// journals.openedition.org/configuracoes/1148; DOI : 10.4000/configuracoes.1148

Este documento foi criado de forma automática no dia 1 Maio 2019.

(c) $\mathrm{CICS}$ 


\title{
Contextos, discursos e percursos na delinquência juvenil feminina
}

\author{
Contexts, discourses and pathways in female juvenile delinquency \\ Contextes, discours et parcours de la délinquance juvénile féminine
}

\author{
Vera Duarte
}

\section{Contextualizações iniciais}

1 Sabemos que o género é uma das variáveis de diferenciação mais consistentes na análise do fenómeno criminal e que, em regra, traz à tona padrões históricos hegemónicos que tradicionalmente associam o masculino à agressão e ao exercício de autoridade e o feminino à figura da vítima (Chesney -Lind, 1997; Messerschmidt, 1997; Abramovay, 2010). Aliás, a associação entre transgressão, violência e masculinidade parece estar tão arraigada nos discursos, nas práticas e nas subjetividades que tem alimentado estereótipos de género pouco atentos à possibilidade de rapazes e raparigas experienciarem e usarem a violência por diferentes razões, sob diferentes circunstâncias e como resultado de diferentes histórias e contextos de pertença de género.

2 Retratada como vítima, a fi gura feminina torna -se invisível como agressora e quando surge no quadro da delinquência perpetua imagens e representações estereotipadas eivadas de interpretações que sugerem a biologização, a sexualização, a patologização e a masculinização dos comportamentos. Tais imagens criam mitos, mitos que se tornam práticas que vão sendo reiteradas pela ação da comunicação social, dos discursos públicos e políticos, das estatísticas e dos estudos científicos, que vão partilhando a convicção de que os desvios juvenis femininos são poucos, pouco importantes e não constituem problema social.

3 A constante secundarização do fenómeno tem resultado, não só em Portugal como também em outros países, na emergência de uma literatura mais sensível ao género que tem vindo a denunciar a carência de um enfoque autónomo sobre a delinquência 
praticada por raparigas ${ }^{1}$, que tende a ser diluída em análises mais amplas sobre a "delinquência juvenil". Esta situação tem tido consequências quer no campo conceptual e analítico, quer nas dimensões da prática e da intervenção preventiva, judicial e (re)educativa, ainda pouco atentas a esta realidade, apesar de ser unânime entre os/as investigadores/as que as raparigas estão mais visíveis na cena da delinquência (Steffensmeier et al, 2005; Luke, 2008; Zahn et al, 2008).

4 A literatura tem -nos apontado, também, para o facto de rapazes e raparigas não se exprimirem da mesma forma, não fazerem as mesmas escolhas e não atribuírem os mesmos sentidos às coisas, por serem diferentes as representações e reproduções quotidianas do género (Chesney -Lind, 1997; Peters, 1998; Arnull e Eagle, 2009; Zahn et al., 2010). Nesta esteira têm vindo a ser identificados alguns dos principais factores de risco na transgressão juvenil feminina: o abuso sexual e físico de que são mais vítimas do que os rapazes; em consequência destes abusos vários fogem de casa e é, neste contexto de fuga ao qual se associam outras práticas desviantes, que são captadas pelo sistema de controlo; os consumos de drogas e álcool, ainda que não sejam mais significativos do que nos rapazes, exacerbam outros problemas; iniciadas na vida sexual de forma mais precoce do que as jovens não delinquentes, a gravidez na adolescência e a gravidez não planeada surge como uma realidade visível; se nos rapazes a escolha dos/as companheiros/as sexuais e/ou românticos pode ser um momento de viragem que leve à diminuição do comportamento delinquente, na rapariga tem um efeito oposto; as raparigas surgem como desproporcionalmente mais problemáticas e apresentam níveis mais altos de problemas de saúde mental (como ansiedade, depressão, distúrbios alimentares e tendências suicidas); a qualidade dos relacionamentos tem um impacto superior nas raparigas; e a puberdade precoce, maturidades inconsistentes e o desejo de adquirir estatuto de adulto parece ser um ativador.

5 Se alguns factores têm sido constantemente associados à delinquência cometida por raparigas, estas não deixam, contudo, de partilhar alguns dos mesmos problemas-tipo que encontramos na construção social da "delinquência juvenil". Contudo, segundo Zahn et al. (2010), estes factores de risco parecem diferir na sensibilidade de exposição aos mesmos e, neste sentido, as dificuldades de adaptação das raparigas tendem a manifestar -se de forma diferente da dos rapazes, o que faz com que a agressão feminina seja qualitativamente diferente (Lanctôt, 2008: 345).

Inscrevendo-se nesta necessidade de dar visibilidade a um fenómeno que tem sido remetido para nota de rodapé, sublinhando a importância de olhar a figura feminina como sujeito ativo na construção da própria vida, este artigo recorre a alguns resultados e reflexões que foram produzidos no âmbito da minha pesquisa de doutoramento ${ }^{3}$ sobre discursos e percursos na "delinquência juvenil" feminina. Para colocar esses resultados em perspetiva, e dar uma visão larga da investigação realizada, procura-se, primeiramente, apresentar alguns dos principais recortes teórico-metodológicos e empíricos da investigação realizada e, de seguida, evidenciar os principais contextos e experiências de vitimação e transgressão, onde as jovens constroem discursivamente os seus percursos. 


\section{Recortes de uma investigação : objetivos e escolhas metodológicas}

7 Aceitando a provocação dos estudos mais recentes que consentem a necessidade de investigações exploratórias que tragam as vozes das raparigas em conflito com a lei para o centro do debate teórico -metodológico sobre a "delinquência juvenil", a pesquisa realizada propôs-se captar discursos e percursos transgressivos, através da análise das experiências, significados e crenças de raparigas em cumprimento de medidas tutelares educativas ${ }^{4}$, em Portugal. Para o efeito, desenvolveu-se uma estratégia de investigação intensiva-qualitativa e trabalharam-se conceitos e métodos disponibilizados por abordagens teóricas sensíveis à compreensão de como as pessoas transformam influências objetivas em iniciativas subjetivas. A leitura e a discussão dos dados foram feitas nas interfaces do interacionismo simbólico, das teorias da ação estruturada e das perspectivas feministas que, embora situadas em níveis analíticos distintos, permitiram colocar o debate na perspectiva do sujeito (feminino), sem perder de vista que as subjetividades são permeadas pelas (im)possibilidades do espelho social que molda performances (de transgressão e de género).

8 Assumindo como referente empírico as jovens a cumprir medida de internamento em Centro Educativo e a executar medidas não institucionais sob acompanhamento das Equipas Tutelares Educativas ${ }^{5}$, analisaram -se 27 processos individuais/ tutelares, de um total de 31, e realizaram -se 19 entrevistas ${ }^{6}$. A análise dos processos possibilitou fazer uma caracterização sociológica da população em estudo e as análises de conteúdo e discurso das entrevistas permitiram, através da construção narrativa (Denzin, 1989), fazer emergir os sentidos e significados das experiências transgressivas nos diferentes contextos interativos.

9 As jovens com medidas tutelares educativas que integram a amostra deste estudo (27 jovens) têm entre os 16 e os 17 anos, são maioritariamente de nacionalidade portuguesa (20/27), ainda que seja de considerar a expressividade de jovens de origem africana (12/27), e residem em zonas desfavorecidas do ponto de vista económico e social. Estão a cumprir medida tutelar educativa principalmente pela prática de ilícitos contra a propriedade, especificamente o roubo (17/27), e contra a integridade física (11/27). São as jovens internadas em Centro Educativo que tendem a refletir maiores fatores de risco e vulnerabilidade em razão da idade, da etnicidade e da classe social.

\section{Contextos de onde nascem vozes, vozes que espelham percursos}

\subsection{Dos contextos...}

10 A partir da análise dos processos individuais e das entrevistas realizadas às jovens foi possível captar trajetórias contextualizadas e situadas em esferas de vida específicas, como a família, a escola, o bairro ou o grupo de pares, onde se cruzam experiências de vitimação e transgressão. É nestas esferas e nestas experiências que as jovens constroem discursivamente os seus percursos. Sabemos como estes contextos estão interconectados 
como uma rede e como várias situações de risco podem ser, simultaneamente, causa e consequência umas das outras.

A família é lugar de onde fogem, mas para onde sempre regressam pelas palavras.

Eu senti -me traída pela minha mãe, pensei que ela se queria ver livre de mim e como ela já me tinha deixado (...) foi mais uma peça, como um puzzle! [Mara, 15 anos, medida tutelar de internamento]

12 As estruturas e dinâmicas familiares surgem como um puzzle onde faltam peças. Marcados por muitas transições, decomposições e recomposições, os contextos familiares destas jovens ficam marcados pela vivência de repetidas rupturas nos vínculos afectivos e relacionais e pela exposição (direta e indireta) a diferentes formas de maus-tratos. São comuns as histórias de abandonos e privações várias, vivenciadas em idades precoces. Encontramos três principais tipos de abandono: a) Abandono pela ausência de um ou dos dois progenitores. A maioria dos agregados não conta com a presença de um dos progenitores biológicos, sendo a figura paterna a que tende a estar ausente do processo educativo. Os principais motivos são o falecimento e a separação/ divórcio; b) Abandono pelo sentimento de insegurança na relação familiar, não encontrando nas figuras parentais o equilíbrio emocional necessário para um desenvolvimento saudável; c) Abandono por via da prática reiterada de maus -tratos. A falta de apoio na/ da família atinge o seu núcleo fundamental de proteção, de afecto e dependência, principalmente quando o maltrato é perpetrado no interior da família. A estas formas de abandono associam-se outros aspectos relacionados com a carência de limites intrafamiliares, a falta de supervisão e comunicação parentais e a ideia de que os quotidianos são geridos pelas próprias jovens. Estas situações estão relacionadas com modelos familiares frágeis, mas também com a dificuldade sentida por estas famílias na organização das responsabilidades profissionais de modo a privilegiar a presença em casa.

As relações familiares assumem, para estas jovens, uma importância significativa e estruturam -se em torno de três grandes imagens. A imagem da idealização de uma proximidade familiar que é concomitante com a descrição de sentimentos negativos face a abusos de que foram vítimas diretas ou indiretas. A segunda imagem é construída em torno da relação com as fi guras educativas, onde a figura da mãe assume a centralidade e com a qual mantêm uma relação de "amor-ódio". É relativamente a ela que expressam frustrações, desamparos e alegrias, e é em torno do não cumprimento das expectativas maternas que as jovens vivem e experienciam os seus fracassos. E, por fim, a relação com os irmãos. Pertencentes a grandes fratrias (de mais de três irmãos), quando têm irmãos com percursos transgressivos (normalmente são mais velhos) é com eles que se identificam, sentem mais afinidades e proximidade, ainda que seja com os mais novos que elas mantêm maior relação e sentimentos de proteção, quase maternal. As raparigas tornam -se muito protetoras dos membros mais vulneráveis (principalmente os irmãos e as avós), assumindo um discurso quase altruísta de proteção.

A escola é vivida do "lado de fora" e não parece fazer parte dos seus projetos.

Chumbei duas vezes, 5. e $6 . .$. foi várias coisas, foi a falta de estudo, foi falta de interesse... não quis mesmo saber... pronto! Faltava, às vezes portava-me mal, não estudava, tinha testes e não estudava, na minha turma a gente também não era assim muito boa (risos) [Anabela, 17 anos, medida tutelar imposição de obrigações]

Apresentando percursos de insucesso escolar, grande parte das jovens (17/27), à data da aplicação da medida tutelar educativa, tinham o 2.. Ciclo, que parece surgir, neste contexto, como um obstáculo difícil de transpôr e onde se intensificam as situações de 
absentismo, desmotivação e as consequentes reprovações. Mais do que não gostar da escola, que surge para as jovens como um lugar de encontros e sociabilidades, é com as aulas que elas não se identificam e com o não gostar de estudar que justificam o seu desinteresse. Por isso, faltam para estar com os amigos e/ ou namorados ou então para ficar em casa.

Não menos significativo é o número de jovens (11/27) às quais se associam problemas comportamentais e disciplinares, que resultaram em suspensões e expulsões. A relação com a escola está longe de ser aquilo que é esperado e estes percursos de insucesso, indisciplina e abandono, associados a outros contextos de risco, acabam por transformar se num trampolim para a entrada no sistema de proteção.

Vimos que é da família e da escola que fogem para ir ter com os/as amigos/ as e que neles/as procuram companhia e apoio emocional e social, compensador das ausências e desestruturações familiares.

Andava por lá...com os meus amigos... passeávamos o dia sem fazer nada... fumar e quê! Não nos cansávamos de não fazer nada [Joana, 15 anos, medida tutelar de internamento]

Todo o contexto de vida destas jovens leva a que estas passem muito do seu tempo fora de casa e, associando-se ao seu grupo de amigos/as, preenchem os quotidianos, fazem as primeiras experimentações e testam os seus limites. Nesta esfera, apresentam traços característicos da adolescência e das feminilidades, ou seja, integram-se em grupo de pares alargados e mistos, de diferentes contextos (de infância, do bairro, da escola). As amizades desenvolvem -se em grupos mais restritos e é, normalmente, com outras raparigas que procuram companhia para ir a festas, passear na comunidade, sair com rapazes e experimentar o risco, como refere Teresa [16 anos, medida tutelar tarefas a favor da comunidade]:

não fazíamos nada, ficávamos na rua... às vezes até íamos à escola, mas nunca entravamos nas aulas sequer... decidíamos ir passear. (...) Éramos só raparigas. E fazíamos de tudo um pouco, tudo.

Se esta experimentação tem um caráter de normalidade na faixa etária em questão, no caso destas jovens, que apresentam um acumular de outros riscos relacionados com o número de contextos com os quais têm ligações negativas, parece colocá-las em situação de risco ou para iniciar comportamentos de risco/ desviantes ou para ficar em risco de sofrer consequências negativas para a saúde, quando a prática destes comportamentos já é visível.

21 No que se refere ao grupo de pares, o que parece constituir-se factor de risco de delinquência é a integração em grupos de pares mais velhos e com prática de comportamentos transgressivos. É normalmente em grupo que cometem mais infrações e com mais frequência, havendo uma tendência para que as raparigas sigam outras raparigas, na esteira do já sugerido por Giordano et al. (2002). Sabemos que o fenómeno da "delinquência juvenil" é um fenómeno grupal, mas o aumento e a gravidade dos ilícitos praticados em co-autoria, por raparigas, têm assumido outra expressão que tem questionado a possibilidade das raparigas estarem a usar de mais violência ${ }^{7}$ e de ver nascer outras motivações que as colocam no caminho de uma procura mais ativa do risco, da experimentação e do divertimento (Batchelor, 2005).

Às amizades de infância, do bairro e/ou da escola, juntam-se, por um lado, as amizades estratégicas e funcionais que nascem das vivências de rua e que, em situações de fuga de casa, permitem encontrar alternativas à própria rua, e, por outro lado, as amizades 
"levadas para" e/ou feitas nas instituições da proteção, como relata Vera [16 anos, medida tutelar de internamento]:

...participei em alguns roubos, agressões, principalmente quando fui para o Lar, fugia muitas vezes com as meninas de lá. Duas das amigas foram para o Lar...e vieram para aqui (Centro Educativo) comigo.

Os Lares de Infância e Juventude entram nos seus discursos com alguma "normalidade". Metade das jovens com medidas tutelares educativas apresenta percursos de institucionalização anteriores, no âmbito da aplicação de medidas de promoção e proteção, ficando visível uma grande mobilidade entre os sistemas de proteção e de justiça juvenis. Em torno destas figuras constroem os seus percursos de vitimação e transgressão, e para elas imputam as culpas do seu comportamento.

Apesar de um número considerável de jovens ter familiares e namorados/ex-namorados identificados com contactos com a justiça e a literatura apontar que este envolvimento tem uma influência significativa nos percursos e nas escolhas das jovens raparigas, os dados não permitiram concluir que estes influenciem mais do que os/as amigos/as. E se em algumas situações podem ser o motor dos comportamentos desviantes, o que parece sobressair é o contacto e a aprendizagem com os/as amigos/as e a procura/gestão de comportamentos de risco.

É importante notar que estes discursos não devem descurar que estas escolhas são enquadradas por constrangimentos estruturais e circunstâncias sociais adversas que podem ser limitativas da sua própria agencialidade (Miller, 2001; Batchelor, 2005).

\section{2. ... aos percursos transgressivos}

Para Bakhtin (1997), os discursos dos sujeitos transportam marcas profundas da sua sociedade, do seu núcleo familiar, das suas experiências, mas também das suposições feitas sobre o que o/a interlocutor/a gostaria ou não de ouvir. Foi neste espaço relacional e dialógico que se construíram os retratos sociológicos das jovens entrevistadas e se procuraram os repertórios interpretativos presentes nos seus discursos. Atribuindo às jovens a condição de "autores da sua vida" e assumindo que é a partir das narrativas que constroem as suas experiências, apercebemo-nos como os motivos da transgressão são diversificados e como as jovens se (re)posicionam face a eles. Umas mostram como a transgressão surge da gestão de sentimentos negativos, angústias e lutos mal resolvidos, originados pelas histórias de maus-tratos, abandonos e institucionalizações. Para outras foi a procura do "risco-aventura" (Spink, 2001), da experimentação e da adrenalina o motor para a prática transgressiva. Os discursos da hetero-determinação (foram as drogas, o namorado/ companheiro, os sentimentos de revolta e raiva, a passagem pela instituição... ), frequentemente se cruzam com os discursos do fui porque quis ou foi por vontade própria. Para outras ainda a transgressão surge como uma exceção, o não sabia o que estava ali a fazer ou foi reação parecem legitimar as suas versões sobre o ocorrido.

Foi nestas dinâmicas e nos diálogos que se estabeleceram com certas categorias expressivas dos seus contextos de vida e das suas experiências (como a vitimação familiar, os percursos de institucionalização, os percursos transgressivos, motivações e significados da transgressão e a condenação moral da transgressão),que foram tomando forma quatro perfis de percursos transgressivos: transgressão enfatizada (por revolta ou por escalada), transgressão-rebelde, transgressão -influência e transgressão circunstancial. 
Eu tenho de explodir, tenho de explodir (...). o que me dava adrenalina era ver as pessoas no chão a chorar... por mais louco que isso pareça. $O$ que me vinha à cabeça era: fizeram -me a mim, tenho de fazer aos outros, porque se não fizer ninguém vai sentir aquilo que eu senti. Mas hoje compreendo que nunca ninguém vai sentir o que eu senti, porque não eram os pais que estavam a bater... [Elisabete, 14 anos, medida tutelar de internamento] metade das jovens entrevistadas (9/19) e a quase totalidade das jovens com medida de internamento em Centro Educativo (7/10). Concentra percursos de maior vitimação familiar, histórias densas e heterogéneas de transgressão e delinquência, institucionalizações sucessivas, em regra desencadeadas pela ação de organismos externos (Escola, Comissão de Proteção de Crianças e Jovens e Polícia), relacionada com a situação de negligência e maus tratos familiares, problemas disciplinares e de comportamento na escola e as fugas de casa. A permanência na(s) instituição(ões) é marcada pelas fugas consecutivas e pelo agravamento dos comportamentos transgressivos.

Este é um percurso bifurcado. As jovens cuja transgressão é enfatizada por revolta organizam as suas narrativas em torno destes sentimentos de revolta, que se materializam na auto e hetero-agressividade. São estes sentimentos que explicam e justificam os comportamentos desviantes (nas suas diversas expressões). Há uma condenação moral aparente da transgressão, mas que é legitimada pelos sentimentos negativos. Na transgressão enfatizada por escalada há a percepção de que o comportamento transgressivo se foi agravando e reforçando ao longo das trajetórias de vida. A motivação para a transgressão não está apenas na gestão dos sentimentos negativos (ainda que esteja presente), mas também na experimentação e no divertimento/ prazer que retiram disso, e que surge relacionado com as vivências de rua com os amigos do bairro e com as sobrevivências na rua, aquando das fugas (de casa e das instituições). À hetero-determinação no envolvimento criminal juntam -se discursos de iniciativa, controlo e prazer associados à prática transgressiva, e pela qual não evidenciam uma condenação moral, mas apenas um arrependimento pós-medida.

As jovens incluídas no percurso de transgressão rebelde (3/19), por outro lado, não apresenta históricos de vitimação familiar significativa, nem registos de permanência em instituições da proteção. As motivações para a transgressão são encontradas nos/as amigos/as, na rebeldia de se ser jovem e no querer testar limites. Os discursos apelam para uma certa auto-determinação no envolvimento transgressivo, como se estivesse nas suas mãos a decisão do início ou do fim, como nos mostra Inês [17 anos, medida tutelar de acompanhamento educativo]:

O meu objectivo é curtir a vida, viver cada dia que passa como se fosse o último. (...) Tudo nesta vida tem risco...ver onde chegas, qual é o teu limite! Eu sou assim, gosto de saber qual é o meu limite. Nesta vida ou morres, ou vais preso ou foges! Existe uma vida tranquila... mas a vida sem risco não é nada, vida só sossego, só sossego, não... não faz sentido... não tem sentido.

Se há jovens cujas narrativas as colocam no centro deste percurso, uma vez que a procura do risco -aventura e dos sentimentos de adrenalina é o que as leva a iniciar e a manter comportamentos transgressivos, outras há em que este percurso surge não no início, enquanto desencadeador da ação, mas na manutenção desses comportamentos, como vimos na transgressão enfatizada por escalada e, como podemos analisar, também, na transgressão-influência. 

influência é, possivelmente, o que reúne histórias de vida mais diversificadas (4/19). Para Verónica [16 anos, medida tutelar de internamento] tudo o que fiz, fiz porque estava completamente drogada. Sónia [18 anos, medida tutelar imposição de obrigações], por sua vez, diz: comecei a fazer porcarias, (...) a tratar mal os meus pais, tudo por causa dele (namorado) (...) comecei a fugir de casa p'ra poder estar com ele.

33 A característica central deste percurso é a hetero-determinação no envolvimento transgressivo e a ideia de que este é resultado da influência de factores externos (drogas, namorados e amigos/as). A centralidade do factor influência secundariza o peso de todas as outras variáveis como os percursos transgressivos, as motivações e significações da transgressão e a condenação moral da transgressão. Por exemplo, sem históricos de vitimação familiar significativa, os problemas relacionais com a família agravam-se devido a esses factores de influência externa. Vão para as instituições e delas fogem por causa desses factores.

As jovens situadas no percurso de transgressão circunstancial, todas com medidas tutelares na comunidade (3/19), organizam as suas narrativas em torno do carácter de exceção e de casualidade que é conferido ao comportamento transgressivo, demarcandose de qualquer identidade desviante ou percurso transgressivo. Exceção porque o ilícito é descrito como uma situação ocasional e acidental. Exceção pois as suas vidas não se organizam em torno da prática transgressiva. Filhas de pais separados, as (novas) dinâmicas familiares tendem a ser estáveis, ainda que criem, nas jovens, alguns discursos marcados por alguma mágoa. Mantêm atividades de lazer tendencialmente normativas e comuns entre os jovens. Apesar de não concordarem com a medida, precisamente pela sua "excepcionalidade", não deixam de condenar o ato, como mostra Luísa [16 anos, medida tutelar de prestação de tarefas a favor da comunidade]:

... eu tinha uma arma (branca) mas era para minha defesa, por causa do que me tinha acontecido. (...). Eu achei que não devia cumprir, porque me estava a tentar defender, mas compreendi porque é a lei... não é por me atacarem que eu tenho direito a andar com armas.

Cada um destes percursos, apesar de supor a existência de coerência entre os elementos contidos em cada tipo, não pretende representar inflexibilidade nas suas categorias. Se há jovens cuja narrativa as coloca no centro das categorias em análise, há outras situações que se mantêm nas margens, tocando categorias vizinhas. Estas margens, que não são contudo periféricas, invocam a diversidade da transgressão feminina e a pluralidade de sentidos e significações possíveis.

\section{Notas conclusivas}

Vimos como o tema da "delinquência juvenil" feminina nos desafia, em vários quadrantes, mas estamos certos que esta é uma discussão que deve ser feita para servir de base a um esforço que coloque as raparigas delinquentes nas preocupações do sistema de justiça juvenil e seja fértil no levantamento de novos questionamentos teóricos e metodológicos. Ao descrever os diferentes tipos de discursos e percursos alerta-se para a importância de pensar a "delinquência juvenil" feminina como heterogénea e como esta perceção é fundamental: na (re)categorização conceptual que tem implicações no debate em torno da construção da sua visibilidade social; nos questionamentos em torno das juventudes femininas e das novas feminilidades; nos debates de superação dos discursos

Configurações, 9 | 2013 
dicotómicos da vitimação versus agencialidade e na produção de políticas e práticas de intervenção sensíveis ao género. Ao dimensionar as jovens como sujeitos sociais abre-se o olhar para a forma como elas constroem os diferentes espaços de agencialidade, em contextos de constrição social e acumulação de riscos.

Mostramos como as jovens não estão passivas e como procuram conquistar o espaço que se abriu para elas, legitimando feminilidades e não propriamente construindo masculinidades, mesmo quando desafiam as noções que elas próprias têm do que é considerado apropriado para as raparigas. Falamos é de outras feminilidades, mais rebeldes, e que combinam práticas convencionais e atípicas de género, ou seja, neste autoempoderamento (self empowerment) que poderia significar transformações nos papéis tradicionais, não é imperativo que se transgridam ou rejeitem todos os papéis femininos tradicionais. A violência perpetrada, a liberdade, a autonomia e a independência que reclamam para si (pelas fugas de casa, pelas experimentações de álcool e drogas, pela prática de ilícitos, entre outros) não deixam de esbarrar na manutenção de discursos e concepções tradicionais de masculinidade e feminilidade, que são utilizados para falar sobre: as responsabilidades familiares e os papéis domésticos, para justificar o maior controlo que os pais tendem a exercer em suas vidas, para falar sobre as vivências da maternidade e como esta tem um efeito de "mudança", para se referirem aos projetos de futuro, também estes trespassados pelas marcas de género, mas, também, para se exprimirem sobre o papel da rapariga na transgressão. Apesar dela poder fazer tudo que os rapazes fazem, neles é normal, eles começam a andar em grupos, nessa vida... mas rapariga...é muito feio.

39 É importante que a sociedade e os vários profissionais diretamente envolvidos sejam sensíveis aos repertórios interpretativos utilizados pelas jovens e reconheçam como estes podem ampliar ou limitar as possibilidades de sentido sobre a transgressão. Parece ser o momento, em parte gerado pela visibilidade de episódios agressivos com raparigas, de começar a desenvolver uma agenda de investigação e intervenção com respeito a este grupo e a esta problemática. Existe hoje uma pequena literatura, mas em crescimento (Peters, 1998; Bloom e Covington, 2001; Zahn et al. 2010), que suporta direções úteis na prossecução de instrumentos de política, avaliação, tratamento e prevenção sensíveis às necessidades e idiossincrasias das raparigas que começam a estar mais representadas no sistema de justiça juvenil. Estas estratégias passam por programas específicos de género, criação de espaços de relação onde as vozes das raparigas sejam valorizadas e ouvidas, formação e capacitação dos profissionais para as especificidades desenvolvimentais e sociológicas das raparigas, mas também num tratamento estatístico sensível ao género.

\section{BIBLIOGRAPHY}

ABRAMOVAY, Miriam (2010), Gangues, género e juventudes: donas de rocha e sujeitos cabulosos, Brasília: Secretaria de Direitos Humanos.

ARNOTT, Rosemary (2010), A girls'eyes view of aggressive adolescent female behavior, tese de doutoramento em Educação, Nova Zelândia: Massey University. 
ARNULL, Elain; EAGLE, Susannah (cood.) (2009), Girls and offending - patterns, perceptions and interventions, Londres: YJB.

ASSIS, Simone, CONSTANTINO, Patrícia (2001), Filhas do Mundo: infracção juvenil feminina no Rio de Janeiro, Rio de Janeiro: Editora FioCruz.

BAKHTIN, Mikael (1997), Marxismo e Filosofi a da Linguagem, São Paulo: Hucitec

BATCHELOR, Susan (2005), “'Prove me the bam!' victimization and agency in the lives of young women who commit violent offences”, Probation Journal, 52 (4), 289 -294.

BLOOM, Barbara; COVINGTON, Stephanie (2001), "Effective Gender Responsive Interventions in Juvenile Justice: Addressing the Lives of Delinquent Girls”, [online], disponível em: http:// www.centerforgenderandjustice.org/pdf/7.pdf [acedido em: 14/10/2010].

BURMAN, Michele, BROWN, Jane e BATCHELOR, Susan (2003), "Taking it to heart: girls and the meaning of violence" in Elizabeth Stanko (ed.), The meanings of violence, Nova Iorque: Routhedge, pp. $71-89$.

CAMPBELL, Anne (1984), The Girls in the Gangs, Oxford: Basil Blackwell.

CARLEN, Pat (1988), Women, crime and poverty, Milton Keynes: Open University Press.

CHESNEY -LIND, Meda (1997), The female offender, California: Sage Publication.

CUNHA, Manuela (2002), Entre o Bairro e a Prisão: tráfico e trajectos, Lisboa: Fim do Século.

DENZIN, Norman (1989), Interpretive biography, Londres: Sage.

DUARTE, Vera (2010), “Através do espelho de Alice: vitimação e agência na infracção juvenil feminina", in Sofia Neves e Marisalva Fávero (org.), Manual de Vitimologia, Coimbra: Almedina, pp. $167-193$.

DUARTE, Vera (2011), Os caminhos de Alice do outro lado do espelho: Discursos e percursos na “delinquência juvenil" feminina, Tese de doutoramento, Braga: Universidade do Minho.

GELSTHORPE, Loraine, WORRAL, Anne (2009), "Looking for Trouble: A Recent History of Girls, Young Women and Youth Justice”, Youth Justice, 9 (3): 209 -223.

GIORDANO, Peggy, CERNKOVICH, Stephen e RUDOLPH, Jennifer (2002), “Gender, crime and desistance: toward a theory of cognitive transformation", American Journal of Sociology, 107 (4): $990-1064$.

HOYT, Stephanie; SCHERER, David (1998), “Female Juvenile Delinquency: Misunderstood by the Juvenile Justice System, Neglected by Social Sciences", Law and Human Behavior, 22(1): 81 -107.

LANCTÔT, Nadine (2008), “A delinquência feminina: a eclosão e a evolução do conhecimento”, in Marc Le Blanc, Marc Ouimet e Denis Szabo (coords.), Tratado de criminologia empírica, Lisboa: Climepsi Editores, pp. $337-371$.

LEOTE DE CARVALHO, Maria João (2010), Do outro lado da cidade: crianças, socialização e delinquência em bairros de realojamento, Tese de doutoramento, Lisboa: Universidade Nova de Lisboa.

LESCHIED, Alan, CUMMINGS, Anne, BRUNSCHOT, Michele, CUNNINGHAM, Alison e SAUNDERS, Angela (2000), Female Adolescent Aggression: A Review of the Literature and the Correlates of Aggression, Ottawa: Solicitor General Canada.

LUKE, Katherine (2008), “Are Girls Really Becoming More Violent? A Critical Analysis”, Affilia. Journal of Women and Social Work, 23(1): 23 -38. 
MARTELEIRA, Joana (2007), “Estudo de caracterização do perfil dos educandos internados nos Centros Educativos do Ministérios da Justiça a 30 de Junho de 2005”, Infância e Juventude, 2: 67 $-186$.

MATOS, Raquel (2008), Vidas raras de mulheres comuns: percursos de vida, significações do crime e construção da identidade em jovens reclusas, Coimbra: Almedina.

MESSERSCHMIDT, James (1997), Crime as structured action: gender, race, classe and crime in the making, Thousand Oaks: Sage.

MESSERSCHMIDT, James (2002), “On gang girls, gender and structured action theory: a reply to Miller”, Theoretical Criminology, 6 (4): 461 -475.

MILLER, Jody (2001), One of the guys: girls, gangs and gender, Nova Iorque: Oxford University Press.

PETERS, Sheila (coord.) (1998), Guiding principles for promising female programming: an inventory of best practices, OJJDP [online], disponível em: http://www.ojjdp.gov/pubs/principles/ch1_1.html [consultado em:19/12/10].

SHAW, Margaret, DUBOIS, Sheryl (1995), "Understanding violence by women: a review of the literature" [online], disponível em: http://www.csc -scc.gc.ca/text/prgrm/fsw/fsw23/toce eng.shtml [consultado em: 2/9/2008].

SPINK, Mary Jane (2001), “Trópicos do discurso sobre risco: risco -aventura como metáfora na modernidade tardia”, Cadernos de Saúde Pública, 17(6): 1277 -1311.

STEFFENSMEIER, Darrell, SCHWARTZ, Jennifer (2003). Trends in Female Crime: It's Still a Man's World . [online], disponível em: http://cooley.libarts.wsu.edu/schwartj/pdf/Schwartz\%20 (Trends).pdf [consultado em: 02/08/2010].

ZAHN, Margaret et al. (2010), "Causes and correlates of girl's delinquency”, OJJDP Girls Study Group: understanding and responding to Girl's Delinquency, Washington: US Offi ce of Justice Programs.

\section{NOTES}

1. Vários têm sido os/as investigadores/as de diferentes áreas científicas e de variados países que têm chamado a atenção para esta ausência de investigação sobre o fenómeno e proposto investigações com raparigas que usam estratégias violentas. Destacam -se: Shaw e Dubois (1995), Leschied, et al. (2000) no Canadá; Campbell (1984), Chesney -Lind (1997), Hoyt e Scherer (1998), Miller (2001), Messerschmidt (2002), Steffensmeier e Schwartz (2003), Zahn et al. (2010) nos EUA; Burman, Batchelor e Brown (2003) na Escócia; Gelsthorpe e Worral (2009), Arnull e Eagle (2009) na Inglaterra; Assis e Constantino (2001), Abramovay (2020) no Brasil; Armott (2010) na Nova Zelândia; Matos (2008), Leote de Carvalho (2010) e Duarte $(2010,2011)$ em Portugal.

2. Assumindo que o facto de qualificar alguém como delinquente releva de uma convenção jurídica e que, nesse sentido, o comportamento delinquente será tão variável como os contextos socioculturais e jurídicos onde está inserido, optou-se por utilizar o conceito de delinquência juvenil entre aspas. Conhecem-se os jogos (sociais, culturais, político-ideológicos e económicos) que levam à etiquetagem e sabe-se que nem todos os delitos e nem todas as pessoas adquirem essa identidade social; tem-se presente a ambiguidade conceptual que tem resultado numa polissemia de propostas terminológicas - jovens delinquentes, infractores, em conflito com a lei, transgressores, desviantes, com perturbações de comportamento, entre outros; e entende -se que uma definição que combine níveis de análise mais restritos e alargados de delinquência nos permite perceber lógicas de percurso e captar comportamentos que procedem não apenas da 
violação do estabelecido em quadros jurídicos, mas de outras atividades onde as raparigas infratoras, segundo a literatura, tendem a construir parte dos seus mundos.

3. Este artigo resulta da minha tese de doutoramento em Sociologia, apresentada à Universidade do Minho em 2011, financiado pela Fundação para a Ciência e Tecnologia, através da atribuição de Bolsa de Investigação.

4. A “delinquência juvenil” em Portugal é enquadrada pela Lei 166/99, de 14 de setembro - Lei Tutelar Educativa - que se aplica a jovens entre os 12 e os 16 anos que tenham cometido factos qualificados pela lei como crime (art. 1.ํ). A estes/as jovens são aplicadas medidas tutelares educativas (na comunidade ou de internamento em Centro Educativo) que visam a educação do/a

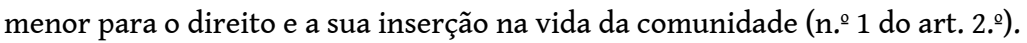

5. A pesquisa decorreu em duas estruturas da DGRS - Direcção -Geral de Reinserção Social. À data da investigação só existia um centro educativo misto (com unidade residencial feminina) em Portugal, com lotação para 12 jovens do sexo feminino. No caso da Equipas Tutelares Educativas, a investigadora só teve autorização para aceder à informação e entrevistar as jovens acompanhadas pelas Equipas da Área da Grande Lisboa.

6. O trabalho de campo decorreu de forma continuada entre Setembro e Novembro de 2008, com regressos pontuais ao terreno durante 2009. Em qualquer um dos contextos de observação, seguiu-se um roteiro ético em que se destaca: os pedidos de autorização; a garantia de uma participação devidamente informada, livre e respeitadora da privacidade e confidencialidade (consentimento informado e despersonificação dos sujeitos) e adequação dos métodos e procedimentos utilizados aos participantes (idade, género, etnicidade...).

7. Num estudo de caracterização do perfi 1 dos educandos internados em CE a 30 de Junho de 2005 (Marteleira, 2007), os jovens que atuavam em grupo eram todos do sexo masculino. Os dados desta investigação apontam que metade das jovens internadas em Centro Educativo (6/12) praticou crimes em co-autoria.

\section{ABSTRACTS}

Este artigo resulta da investigação que foi desenvolvida no âmbito da minha tese de doutoramento em Sociologia que procurou entender a problemática da delinquência juvenil feminina, especificamente as experiências e os significados da transgressão nos percursos de vida de raparigas. Assumindo como referente empírico as jovens em cumprimento de medidas tutelares educativas analisaram-se processos individuais e realizaram -se entrevistas, cujo cruzamento permitiu explorar os contextos e os discursos dominantes e traçar percursos transgressivos.

This article results from a research that was developed as part of my doctoral thesis in sociology about the experiences and meaning of transgression in the life paths of girls. Assuming that the empirical referent of this study included girls in compliance with educational court orders, individual cases were analysed and interviews were carried out. Their intersection allowed for the exploration of contexts and dominant discourses, and of pathways of transgression.

Cet article est le résultat de la recherche qui a été réalisé dans le cadre de ma thèse de doctorat en sociologie qui a eu pour but de comprendre le problème de la délinquance juvénile féminine, et en particulier les expériences et les significations de la transgression dans les trajets de la vie 
des jeunes filles. En ayant comme référence empirique des jeunes filles soumises à des mesures de tutelle éducative, nous avons analysé les dossiers individuels et réalisé des entretiens qui ont permis d'explorer les contextes et les discours dominants et de définir les parcours transgressifs.

INDEX

Mots-clés: délinquance juvénile, délinquance féminine, parcours transgressifs

Keywords: juvenile delinquency, girls' delinquency, transgressive pathways

Palavras-chave: delinquência juvenil, percursos transgressivos, delinquência feminina

\section{AUTHOR}

\section{VERA DUARTE}

Professora auxiliar no Instituto Superior da Maia (ISMAI). Investigadora no Centro de Investigação em Ciências Sociais da Universidade do Minho (CICS/UM),

vduarte@docentes.ismai.pt, veraduarte77@gmail.com 